\title{
Ionization Potentials and Radii of Atoms and Ions of Element 105 (unnilpentium) and Ions of Tantalum Derived from Multiconfiguration Dirac-Fock Calculations
}

\author{
By B. Fricke, Elijah Johnson ${ }^{a}$ \\ Department of Physics, University of Kassel, D-3500 Kassel, Germany \\ and Glorivee Martinez Rivera \\ Isidro A. Sanchez High School, Luquillo, Puerto Rico 00773, USA \\ (Received August 10, 1992)
}

Element 105 / Ionization potentials / Multiconfiguration relativistic Dirac-Fock calculations / Standard electrode potentials / Group $5 b$ elements

\begin{abstract}
Multiconfiguration relativistic Dirac-Fock (MCDF) values were calculated for the first five ionization potentials of element 105 (unnilpentium) and of the other group $5 b$ elements $(\mathrm{V}, \mathrm{Nb}$, and Ta). Some of these ionization potentials in electron volts $(\mathrm{eV})$ with uncertainties are: $105(0), 7.4 \pm 0.4 ; 105(1+), 16.3 \pm 0.2$; $105(2+), \quad 24.3 \pm 0.2 ; \quad 105(3+), \quad 34.9 \pm 0.5 ;$ and $105(4+)$, $44.9 \pm 0.1$. Ionization potentials for $\mathrm{Ta}(1+), \mathrm{Ta}(2+)$, and $\mathrm{Ta}(3+)$ were also calculated. Accurate experimental values for these ionization potentials are not available. Ionic radii are presented for the $2+, 3+, 4+$, and $5+$ ions of element 105 and for the +2 ions of vanadium and niobium. These radii for vanadium and niobium are not available elsewhere. The ionization potentials and ionic radii obtained are used to determine some standard electrode potentials for element 105. Born-Haber cycles and a form of the Born equation for the Gibbs free energy of hydration of ions were used to calculate the standard electrode potentials.
\end{abstract}

\section{Introduction}

In a recent paper [1] the first four ionization potentials and parameters for the radii of the corresponding ions were presented for element 104. These results were obtained from multiconfiguration Dirac-Fock (MCDF) calculations [2, 3]. In a second [4] paper these results were used to predict some thermodynamic properties of selected compounds and aqueous solutions of element 104 . This paper presents ionization potentials and ionic radii for element 105 . These results on element 105 were also obtained by MCDF calculations.

The first five ionization potentials of element 105 are presented here. Values for these have not been published elsewhere. Practical MCDF calculations of the type discussed here [5] yield values of the MCDF ionization potentials which have uncertainties associ-

\footnotetext{
a Permanent address: Chemistry Division, Oak Ridge National Laboratory, P.O. Box 2008, Oak Ridge, Tennessee 378316375, USA.
}

ated with them. The size of these uncertainties were reduced by using an extrapolation procedure which is based on the periodic law of the chemical elements. The procedure also yielded values for the ionization potentials of three ions of tantalum. Only the first and fifth ionization potential of tantalum have been accurately determined by experiments $[6,7,8]$. Radii for the ions involved were also obtained.

A main motivation for the work presented here was to obtain ionization potentials and ionic radii which were accurate enough to be used to predict some chemical properties of element 105 . Such predictions are usually based on a particular Born-Haber cycle $[9$, $10,11]$. The predictions involve heats and entropies of sublimation, ionization potentials, heats and entropies of formation, and heats and entropies of solution. The heats of formation and solution depend on ionic radii.

A significant amount of experimental results have been obtained $[12,13,14]$ for element 105 . These results are mostly concerned with the properties of various salts and aqueous solutions of the element. Experimental studies of bromide and fluoride complexes of element 105 have been performed [12, 13]. One conclusion from the experiments is that the +5 oxidation state is the most stable oxidation state in aqueous solution [14]. The rate of production of element 105 that has been achieved is one atom at a time and the half-life of the longest lived isotope is 40 seconds. This makes the experimental results difficult to obtain. Theoretical results such as those presented in this article should help in the planning of experiments and in the interpretation of data.

In section II the technique used to obtain ionization potentials and ionic radii is presented. In section III values for ionization potentials, ionic radii, and standard electrode potentials are presented. Some conclusions are presented in section IV.

\section{Method}

Ionization potentials and parameters for the ionic radii were obtained from solutions of the Dirac-Fock 
Table 1. Configurations in the non-relativistic nomenclature used in MCDF calculations for positive parity states ${ }^{a}$

\begin{tabular}{|c|c|c|c|c|c|}
\hline \multicolumn{6}{|c|}{$\begin{array}{c}\text { Configurations for Charge (q) } \\
\text { plus [Core }{ }^{b} \text { ] }\end{array}$} \\
\hline$(0)$ & $(+1)$ & $(+2)$ & $(+3)$ & $(+4)$ & $(+5)$ \\
\hline $\begin{array}{l}(n-1) d^{3} n s^{2} \\
(n-1) d^{4} n s \\
(n-1) d^{5} \\
(n-1) d^{3} n p^{2} \\
(n-1) d^{2} n s n p^{2} \\
(n-1) d n s^{2} n p^{2} \\
(n-1) d n p^{4} \\
n s n p^{4}\end{array}$ & $\begin{array}{l}(n-1) d^{2} n s^{2} \\
(n-1) d^{3} n s \\
(n-1) d^{4} \\
n s^{2} n p^{2} \\
(n-1) d n s n p^{2} \\
(n-1) d^{2} n p^{2} \\
n p^{4}\end{array}$ & $\begin{array}{l}(n-1) d n s^{2} \\
(n-1) d^{2} n s \\
(n-1) d^{3} \\
(n-1) d n p^{2} \\
n s n p^{2}\end{array}$ & $\begin{array}{l}(n-1) d^{2} \\
(n-1) d n s \\
n s^{2} \\
n p^{2}\end{array}$ & $\begin{array}{l}(n-1) d \\
n s\end{array}$ & \\
\hline $\begin{array}{l}J=1 / 2 ; 88^{c} \\
J=3 / 2 ; 142\end{array}$ & $\begin{array}{l}J=0 ; 29 \\
J=1 ; 45 \\
J=2 ; 70\end{array}$ & $\begin{array}{l}J=1 / 2 ; 13 \\
J=3 / 2 ; 21\end{array}$ & $\begin{array}{l}J=0 ; 5 \\
J=1 ; 3 \\
J=2 ; 7\end{array}$ & $\begin{array}{l}J=1 / 2 ; 1 \\
J=3 / 2 ; 1\end{array}$ & $J=0 ; 1$ \\
\hline
\end{tabular}

a $n$ is the principal quantum number $(4,5,6$, and 7 for $\mathrm{V}, \mathrm{Nb}$, Ta, and element 105 , respectively).

${ }^{b}$ Core $=\mathrm{Ar}$ for $\mathrm{V} ; \mathrm{Kr}$ for $\mathrm{Nb} ; \mathrm{Xe}(4 f)^{14}$ for $\mathrm{Ta} ; \mathrm{Rn}(5 f)^{14}$ for element 105.

c The number of configurations included in the calculation follows the associated $J$ values.

Table 2. Configurations in the non-relativistic nomenclature used in MCDF calculations for negative parity states ${ }^{2}$

\begin{tabular}{|c|c|c|c|c|c|}
\hline \multicolumn{6}{|c|}{$\begin{array}{c}\text { Configuration for Charge (q) } \\
\left.\text { plus [Core }{ }^{b}\right]\end{array}$} \\
\hline$(0)$ & $(+1)$ & $(+2)$ & $(+3)$ & $(+4)$ & $(+5)^{c}$ \\
\hline $\begin{array}{l}(n-1) d^{4} n p \\
(n-1) d^{3} n s n p \\
(n-1) d^{2} n s^{2} n p \\
(n-1) d^{2} n p^{3} \\
(n-1) d n s n p^{3} \\
n s^{2} n p^{3} \\
n p^{5}\end{array}$ & $\begin{array}{l}(n-1) d^{3} n p \\
(n-1) d^{2} n s n p \\
(n-1) d n s^{2} n p \\
(n-1) d n p^{3} \\
n s n p^{3}\end{array}$ & $\begin{array}{l}(n-1) d^{2} n p \\
(n-1) d n s n p \\
n s^{2} n p \\
n p^{3}\end{array}$ & $\begin{array}{l}(n-1) d n p \\
n s n p\end{array}$ & $n p$ & \\
\hline $\begin{array}{l}J=1 / 2 ; 88^{\mathfrak{c}} \\
J=3 / 2 ; 145\end{array}$ & $\begin{array}{l}J=0 ; 20 \\
J=1 ; 53 \\
J=2 ; 65\end{array}$ & $\begin{array}{l}J=1 / 2 ; 13 \\
J=3 / 2 ; 22\end{array}$ & $\begin{array}{l}J=0 ; 2 \\
J=1 ; 5 \\
J=2 ; 5\end{array}$ & $\begin{array}{l}J=1 / 2 ; 1 \\
J=3 / 2 ; 1\end{array}$ & $J=0 ; 1$ \\
\hline
\end{tabular}

\footnotetext{
a $n$ is the principal quantum number $(4,5,6$, and 7 for $\mathrm{V}, \mathrm{Nb}, \mathrm{Ta}$, and element 105 , respectively).

b Core $=\mathrm{Ar}$ for $\mathrm{V} ; \mathrm{Kr}$ for $\mathrm{Nb} ; \mathrm{Xe}(4 f)^{14}$ for Ta; $\mathrm{Rn}(5 f)^{14}$ for element 105.

c The number of configurations included in the calculations follows the associated $J$ value.
}

equation of quantum mechanics. The general theory of the Dirac-Fock equation is presented elsewhere [2, 3]. This equation was solved using the computer program of J.-P. Desclaux [5]. To obtain results of sufficient accuracy, an extrapolation procedure was used. This procedure involves the MCDF and experimental ionization potentials for the three elements of group $5 \mathrm{~b}$ in the periodic table of the chemical elements that are above element 105 . These three elements are vanadium, niobium, and tantalum.

The basis functions used are linear combinations of Slater determinants. Each basis state (a configuration state function [15]) is an eigenfunction of both the square and the $z$-component of the total angular momentum operators. The single particle wavefunctions which build up the Slater determinants are four component spinors where each component is a product of spherical harmonics and radial functions. The Breit interaction was included by perturbation. The two radial functions (large and small components) together with the expansion coefficients of the configuration state functions were obtained by solving the Dirac-Fock equations in an iterative procedure such that the system is self-consistent.

Solutions of the MCDF equation were found by iteration from initial functions for the radial part of the single particle wave functions. The initial radial part of the single particle wave functions were the solutions obtained for a specific single configuration solution of the Dirac-Fock equation for the $2+$ charged ion of the atom of interest. For vanadium, niobium, tantalum, and element 105, these single configurations were $[\mathrm{Ar}](3 d)^{1}(4 s)^{1}(4 p)^{1}, \quad[\mathrm{Kr}]$ $(4 d)^{1}(5 s)^{1}(5 p)^{1},[\mathrm{Xe}](4 f)^{14}(5 d)^{1}(6 s)^{1}(6 p)^{1}$, and [Rn] $(5 f)^{14}(6 d)^{1}(7 s)^{1}(7 p)^{1}$, respectively. For these specific single configurations, solutions for the $2+$ charged ions were found by iteration using Thomas-Fermi radial functions as the initial functions [5] with both the total angular momentum and $z$-component of the total angular momentum equal to $3 / 2$. 
Table 3. Calculated electronic ground states for $\mathrm{V}, \mathrm{Nb}, \mathrm{Ta}$, and element 105 in the charge states 0 to +5

\begin{tabular}{|c|c|c|c|c|c|}
\hline Element & $\begin{array}{l}\text { no. of } \\
\text { conf. }\end{array}$ & $\begin{array}{l}\text { Angular } \\
\text { momentum } \\
\text { and } \\
\text { parity }\end{array}$ & $\begin{array}{l}\text { Dominant conf } \\
\text { weights in perce }\end{array}$ & & $\begin{array}{l}\text { Total energy } \\
\text { in } \mathrm{eV}\end{array}$ \\
\hline V & 142 & $3 / 2+$ & $\begin{array}{l}{[\mathrm{Ar}]} \\
(3 d)^{3}(4 s)^{2} \\
(3 d)^{3}(4 p)^{2}\end{array}$ & $\begin{array}{r}91.7 \\
7.3\end{array}$ & -25791.379 \\
\hline $\mathrm{Nb}$ & 142 & $3 / 2+$ & $\begin{array}{l}{[\mathrm{Kr}]} \\
(4 d)^{3}(5 s)^{2} \\
(4 d)^{3}(5 p)^{2} \\
(4 d)^{2}(5 s)^{1}(5 p)^{2} \\
(4 d)^{4}(5 s)^{1}\end{array}$ & $\begin{array}{r}89.4 \\
6.3 \\
2.4 \\
1.8\end{array}$ & -103803.108 \\
\hline Ta & 142 & $3 / 2+$ & $\begin{array}{l}{[\mathrm{Xe}](4 f)^{14}} \\
(5 d)^{3}(6 s)^{2} \\
(5 d)^{3}(6 p)^{2} \\
(5 d)^{2}(6 s)^{1}(6 p)^{2} \\
(5 d)^{4}(6 s)^{1}\end{array}$ & $\begin{array}{r}88.6 \\
4.9 \\
3.9 \\
2.1\end{array}$ & -424240.531 \\
\hline 105 & 142 & $3 / 2+$ & $\begin{array}{l}{[\mathrm{Rn}](5 f)^{14}} \\
(6 d)^{3}(7 s)^{2} \\
(6 d)^{2}(7 s)^{1}(7 p)^{2} \\
(6 d)^{3}(7 p)^{2} \\
(6 d)^{4}(7 s)^{1} \\
(6 d)^{1}(7 s)^{2}(7 p)^{2} \\
(6 d)^{5}\end{array}$ & $\begin{array}{r}87.1 \\
4.4 \\
3.8 \\
2.4 \\
1.6 \\
0.6\end{array}$ & -1077521.550 \\
\hline $\mathrm{V}(1+)$ & 45 & $1+$ & $\begin{array}{l}{[\mathrm{Ar}]} \\
(3 d)^{3}(4 s)^{1}\end{array}$ & 100.0 & -25784.801 \\
\hline $\mathrm{Nb}(1+)$ & 29 & $0+$ & $\begin{array}{l}{[\mathrm{Kr}]} \\
(4 d)^{4}\end{array}$ & 99.6 & -103796.933 \\
\hline $\mathrm{Ta}(1+)$ & 45 & $1+$ & $\begin{array}{l}{[\mathrm{Xe}](4 f)^{14}} \\
(5 d)^{3}(6 s)^{1}\end{array}$ & 99.6 & -424233.709 \\
\hline $105(1+)$ & 70 & $2+$ & $\begin{array}{l}{[\operatorname{Rn}](5 f)^{14}} \\
(6 d)^{2}(7 s)^{2} \\
(6 d)^{3}(7 s)^{1} \\
(6 d)^{4} \\
(6 d)^{2}(7 p)^{2}\end{array}$ & $\begin{array}{r}93.0 \\
3.4 \\
1.5 \\
0.9\end{array}$ & -1077515.450 \\
\hline $\mathrm{V}(2+)$ & 21 & $3 / 2+$ & $\begin{array}{l}{[\mathrm{Ar}]} \\
(3 d)^{3}\end{array}$ & 100.0 & -25771.186 \\
\hline $\mathrm{Nb}(2+)$ & 21 & $3 / 2+$ & $\begin{array}{l}{[\mathrm{Kr}]} \\
(4 d)^{3}\end{array}$ & 100.0 & -103783.846 \\
\hline $\operatorname{Ta}(2+)$ & 21 & $3 / 2+$ & $\begin{array}{l}{[\mathrm{Xe}](4 f)^{14}} \\
(5 d)^{3} \\
(5 d)^{2}(6 s)^{1}\end{array}$ & $\begin{array}{r}98.9 \\
0.8\end{array}$ & -424219.598 \\
\hline $105(2+)$ & 21 & $3 / 2+$ & $\begin{array}{l}{[\mathrm{Rn}](5 f)^{14}} \\
(6 d)^{3} \\
(6 d)^{2}(7 s)^{1} \\
(6 d)^{1}(7 s)^{2} \\
(6 d)^{1}(7 p)^{2}\end{array}$ & $\begin{array}{r}7.0 \\
75.0 \\
16.2 \\
7.3 \\
1.3\end{array}$ & -1077500.631 \\
\hline $\mathrm{V}(3+)$ & 7 & $2+$ & $\begin{array}{l}{[\mathrm{Ar}]} \\
(3 d)^{2}\end{array}$ & 100.0 & -25742.987 \\
\hline $\mathrm{Nb}(3+)$ & 7 & $2+$ & $\begin{array}{l}{[\mathrm{Kr}]} \\
(4 d)^{2}\end{array}$ & 100.0 & -103759.642 \\
\hline $\mathrm{Ta}(3+)$ & 7 & $2+$ & $\begin{array}{l}{[\mathrm{Xe}](4 f)^{14}} \\
(5 d)^{2} \\
(5 d)^{1}(6 s)^{1}\end{array}$ & $\begin{array}{r}99.7 \\
0.3\end{array}$ & -424196.539 \\
\hline $105(3+)$ & 7 & $2+$ & $\begin{array}{l}{[\operatorname{Rn}](5 f)^{14}} \\
(6 d)^{2} \\
(6 d)^{1}(7 s)^{1}\end{array}$ & $\begin{array}{r}90.4 \\
9.6\end{array}$ & -1077476.858 \\
\hline $\mathrm{V}(4+)$ & 1 & $3 / 2+$ & $\begin{array}{l}{[\mathrm{Ar}]} \\
(3 d)^{1}\end{array}$ & 100.0 & -25697.187 \\
\hline $\mathrm{Nb}(4+)$ & 1 & $3 / 2+$ & $\begin{array}{l}{[\mathrm{Kr}]} \\
(4 d)^{+}\end{array}$ & 100.0 & -103722.900 \\
\hline $\mathrm{Ta}(4+)$ & 1 & $3 / 2+$ & $\begin{array}{l}{[\mathrm{Xe}](4 f)^{14}} \\
(5 d)^{1}\end{array}$ & 100.0 & -424161.513 \\
\hline $105(4+)$ & 1 & $3 / 2+$ & $\begin{array}{l}{[\operatorname{Rn}](5 f)^{14}} \\
(6 d)^{1}\end{array}$ & 100.0 & -1077444.121 \\
\hline $\begin{array}{l}\mathrm{V}(5+) \\
\mathrm{Nb}(5+) \\
\mathrm{Ta}(5+) \\
105(5+)\end{array}$ & $\begin{array}{l}1 \\
1 \\
1 \\
1\end{array}$ & $\begin{array}{l}0+ \\
0+ \\
0+ \\
0+\end{array}$ & $\begin{array}{l}{[\mathrm{Ar}]} \\
{[\mathrm{Kr}]} \\
{[\mathrm{Xe}](4 f)^{14}} \\
{[\mathrm{Rn}](5 f)^{14}}\end{array}$ & $\begin{array}{l}100.0 \\
100.0 \\
100.0 \\
100.0\end{array}$ & $\begin{array}{r}-25632.948 \\
-103673.400 \\
-424114.389 \\
-1077400.555\end{array}$ \\
\hline
\end{tabular}


Table 4. Promotion energies of selected atoms and ions

\begin{tabular}{|c|c|c|c|c|}
\hline $\begin{array}{l}\text { Atom } \\
\text { or } \\
\text { ion }\end{array}$ & $\begin{array}{l}\text { Transition between ground and } \\
\text { excited configuration }\end{array}$ & $\begin{array}{c}\text { MCDF } \\
\text { energy } \\
(\mathrm{eV})\end{array}$ & $\begin{array}{l}\text { Exp. } \\
\text { energy } \\
(\mathrm{eV})\end{array}$ & $\begin{array}{c}\text { Difference } \\
\text { (MCDF-Exp) } \\
(\mathrm{eV})\end{array}$ \\
\hline $\mathrm{V}(0)$ & $(3 d)^{3}(4 s)^{2}(J=3 / 2+)-(3 d)^{3}(4 s)^{2}(J=1 / 2+)$ & 1.70 & 1.18 & 0.52 \\
\hline$v(1+)$ & $(3 d)^{3}(4 s)^{1}(J=1+)-(3 d)^{3}(4 s)^{1}(J=2+)$ & 0.01 & 0.01 & 0.00 \\
\hline $\mathrm{V}(2+)$ & $(3 d)^{3}(J=3 / 2+)-(3 d)^{3}(J=1 / 2+)$ & 1.83 & 1.39 & 0.44 \\
\hline$V(3+)$ & $(3 d)^{2}(J=2+)-(3 d)^{2}(J=0+)$ & 2.05 & 1.63 & 0.42 \\
\hline $\mathrm{V}(4+)$ & $(3 d)^{1}(J=3 / 2+)-(4 d)^{1}(J=1 / 2+)$ & 18.21 & 18.36 & -0.15 \\
\hline $\mathrm{Nb}(0)$ & $(4 d)^{3}(5 s)^{2}(J=3 / 2+)-(4 d)^{4}(5 s)^{1}(J=1 / 2+)$ & 0.16 & -0.14 & 0.30 \\
\hline $\mathrm{Nb}(1+)$ & $(4 d)^{4}(J=0+)-(4 d)^{3}(5 s)^{1}(J=1+)$ & 0.11 & 0.29 & -0.18 \\
\hline $\mathrm{Nb}(2+)$ & $(4 d)^{3}(J=3 / 2+)-(4 d)^{3}(J=1 / 2+)$ & 1.36 & - & - \\
\hline $\mathrm{Nb}(3+)$ & $(4 d)^{2}(J=2+)-(4 d)^{2}(J=0+)$ & 1.50 & 1.20 & 0.30 \\
\hline $\mathrm{Nb}(4+)$ & $(4 d)^{1}(J=3 / 2+)-(5 s)^{1}(J=1 / 2+)$ & 9.32 & 9.41 & -0.09 \\
\hline $\mathrm{Ta}(0)$ & $(5 d)^{3}(6 s)^{2}(J=3 / 2+)-(5 d)^{3}(6 s)^{2}(J=1 / 2+)$ & 0.96 & 0.75 & 0.21 \\
\hline $\operatorname{Ta}(1+)$ & $(5 d)^{3}(6 s)^{1}(J=1+)-(5 d)^{2}(6 s)^{2}(J=2+)$ & 0.32 & 0.39 & -0.07 \\
\hline $\mathrm{Ta}(2+)$ & $(5 d)^{3}(J=3 / 2+)-(5 d)^{3}(J=1 / 2+)$ & 1.10 & - & - \\
\hline $\mathrm{Ta}(3+)$ & $(5 d)^{2}(J=2+)-(5 d)^{2}(J=0+)$ & 1.59 & - & - \\
\hline $\mathrm{Ta}(4+)$ & $(5 d)^{1}(J=3 / 2+)-(6 s)^{1}(J=1 / 2+)$ & 5.86 & - & - \\
\hline $105(0)$ & $(6 d)^{3}(7 s)^{2}(J=3 / 2+)-(6 d)^{3}(7 s)^{2}(J=1 / 2+)$ & 1.00 & - & - \\
\hline $105(1+)$ & $(6 d)^{2}(7 s)^{2}(J=2+)-(6 d)^{2}(7 s)^{2}(J=0+)$ & 0.76 & - & - \\
\hline $105(2+)$ & $(6 d)^{1}(7 s)^{2}(J=3 / 2+)-(6 d)^{2}(7 s)^{1}(J=1 / 2+)$ & 1.90 & - & - \\
\hline $105(3+)$ & $(6 d)^{2}(J=2+)-(6 d)^{1}(7 s)^{1}(J=1+)$ & 0.48 & - & - \\
\hline $105(4+)$ & $(6 d)^{1}(J=3 / 2+)-(7 s)^{1}(J=1 / 2+)$ & 1.90 & - & - \\
\hline
\end{tabular}

The basis sets used to find solutions to the DiracFock equation are given in Tables 1 and 2 . Table 1 is for even parity states and Table 2 is for odd parity states. In these tables the charge state is at the top of each column of basis functions. Below the basis function, the angular momentum eigenvalues used along with the number of configurations used in the calculation are given. The MCDF calculations include all possible configuration state functions which can be constructed from the relativistic $n s, n p_{1 / 2}, n p_{3 / 2}$, $(n-1) d_{3 / 2}$, and $(n-1) d_{5 / 2}$ single particle wavefunctions for a specific total angular momentum, $z$-component of the total angular momentum, and parity. Examination of the expansion coefficients for the configurations used to find solutions of the MCDF equation shows that some configurations make a small contribution to the wave functions, but the configurations used were not chosen on the basis of the significance of their contributions to the wave functions but on the basis of completeness. For convenience, the $z$-component was always set equal to the total angular momentum in the calculations. Table 1 lists the six possibilities employed for positive parity states for the neutral to $5+$ ions. Column I lists all combinations of the single particle wavefunctions in the non-relativistic nomenclature for the MCDF calculations on the neutral group $5 b$ elements where 5 electrons are distributed in the valence orbitals; columm II lists the single ionized species with 4 active electrons; etc.

In Table 3, for each atom and charge state the number of configurations in the calculation, the angular momentum eigenvalue, the parity, the dominant configurations and corresponding weights, and the energy are given for the lowest electronic states obtained by MCDF calculations using basis sets given in Tables 1 and 2. Except for $\mathrm{Nb}(0)$ and $\mathrm{V}(1+)$ the
Table 5. Experimental single ionization potentials for group $5 \mathrm{~b}$ elements

\begin{tabular}{lllc}
\hline Element & $\begin{array}{c}\text { Experimental } \\
\text { ionization } \\
\text { potential } \\
\text { in inverse } \\
\text { centimeters }\end{array}$ & $\begin{array}{c}\text { Experimental } \\
\text { ionization } \\
\text { potential } \\
\text { in } \mathrm{eV}^{\mathrm{a}}\end{array}$ & Reference \\
& & & \\
\hline $\mathrm{V}(0)$ & 54400 & 6.74 & 6 \\
$\mathrm{Nb}(0)$ & 55511 & 6.8825 & 6 \\
$\mathrm{Ta}(0)$ & 63600 & 7.89 & 6 \\
$\mathrm{~V}(1+)$ & 118200 & 14.65 & 6 \\
$\mathrm{Nb}(1+)$ & 115500 & 14.32 & 6 \\
$\mathrm{Ta}(1+)$ & $123000 \pm 2420$ & $15.2 \pm 0.3$ & 7 \\
$\mathrm{~V}(2+)$ & 236400 & 29.310 & 19 \\
$\mathrm{Nb}(2+)$ & 202000 & 25.04 & 6 \\
$\mathrm{Ta}(2+)$ & 376730 & 46.709 & 6 \\
$\mathrm{~V}(3+)$ & 308600 & 38.26 & 6 \\
$\mathrm{Nb}(3+)$ & - & - & $19 \mathrm{~b}$ \\
$\mathrm{Ta}(3+)$ & 526532 & 65.2822 & 6 \\
$\mathrm{~V}(4+)$ & 407700 & 50.55 & 8 \\
$\mathrm{Nb}(4+)$ & 389340 & 48.272 & \\
$\mathrm{Ta}(4+)$ & & - & \\
\hline
\end{tabular}

a 8065.5410 inverse centimeters $=1 \mathrm{eV}$.

ground state configurations presented in Table 3 are in agreement with experimental results [6]. The ground state found experimentally for $\mathrm{V}(1+)$ has a $(3 d)^{4}$ configuration and a total angular momentum eigenvalue of zero. The MCDF ground state for $\mathrm{V}(1+)$ has a $(3 d)^{3}(4 \mathbf{s})^{1}$ configuration and a total angular momentum of one. The MCDF ground state for $\mathrm{V}(1+)$ is 0.34 electron volts lower in energy than the MCDF state with a $(3 d)^{4}$ configuration and a total angular momentum of zero. The ground state found experimentally for $\mathrm{Nb}(0)$ has a $(4 d)^{4}(5 s)^{1}$ configuration and a total angular momentum eigenvalue of $1 / 2$. The MCDF ground state for $\mathrm{Nb}(0)$ has a $(4 d)^{3}(5 s)^{2}$ con- 
Table 6. Single ionization potentials for group $5 b$ elements. The values in parentheses are estimates

\begin{tabular}{|c|c|c|c|c|c|c|}
\hline $\begin{array}{l}\text { Change } \\
\text { in state }\end{array}$ & $\begin{array}{l}\text { Element } \\
\text { (q) }\end{array}$ & $\begin{array}{l}\text { Transition between } \\
\text { configurations } \\
\text { (see Table 3) }\end{array}$ & $\begin{array}{l}\text { MCDF } \\
\text { IP in } \\
\text { eV }\end{array}$ & $\begin{array}{l}\text { Exp. } \\
\text { IP in } \\
\mathrm{eV}\end{array}$ & Alpha & Beta \\
\hline \multirow[t]{4}{*}{$(0)-(1+)$} & $\mathrm{V}(0)$ & $(3 d)^{3}(4 s)^{2}(J=3 / 2+)-(3 d)^{3}(4 s)^{1}(J=1+)$ & 6.58 & 6.74 & 0.16 & \\
\hline & $\mathrm{Nb}(0)$ & $(4 d)^{3}(5 s)^{2}(J=3 / 2+)-(4 d)^{4}(J=0+)$ & 6.18 & 6.8825 & 0.70 & 0.54 \\
\hline & $\mathrm{Ta}(0)$ & $(5 d)^{3}(6 s)^{2}(J=3 / 2+)-(5 d)^{3}(6 s)^{1}(J=1+)$ & 6.82 & 7.89 & 1.07 & 0.37 \\
\hline & $105(0)$ & $(6 d)^{3}(7 s)^{2}(J=3 / 2+)-(6 d)^{2}(7 s)^{2}(J=2+)$ & 6.10 & (7.37) & $(1.27)$ & $(0.20)$ \\
\hline \multirow{4}{*}{$(1+)-(2+)$} & $V(1+)$ & $(3 d)^{3}(4 s)^{1}(J=1+)-(3 d)^{3}(J=3 / 2+)$ & 13.62 & 14.65 & 1.03 & \\
\hline & $\mathrm{Nb}(1+)$ & $(4 d)^{4}(J=0+)-(4 d)^{3}(J=3 / 2+)$ & 13.09 & 14.32 & 1.23 & 0.20 \\
\hline & $\operatorname{Ta}(1+)$ & $(5 d)^{3}(6 s)^{1}(J=1+)-(5 d)^{3}(J=3 / 2+)$ & 14.11 & $(15.48)$ & $(1.37)$ & $(0.137)$ \\
\hline & $105(1+)$ & $(6 d)^{2}(7 s)^{2}(J=2+)-(6 d)^{3}(J=3 / 2+)$ & 14.82 & $(16.26)$ & $(1.44)$ & $(0.074)$ \\
\hline \multirow[t]{4}{*}{$(2+)-(3+)$} & $V(2+)$ & $(3 d)^{3}(J=3 / 2+)-(3 d)^{2}(J=2+)$ & 28.20 & 29.310 & 1.11 & \\
\hline & $\mathrm{Nb}(2+)$ & $(4 d)^{3}(J=3 / 2+)-(4 d)^{2}(J=2+)$ & 24.20 & 25.04 & 0.84 & -0.27 \\
\hline & $\mathrm{Ta}(2+)$ & $(5 d)^{3}(J=3 / 2+)-(5 d)^{2}(J=2+)$ & 23.06 & $(23.72)$ & $(0.66)$ & $(-0.185)$ \\
\hline & $105(2+)$ & $(6 d)^{3}(J=3 / 2+)-(6 d)^{2}(J=2+)$ & 23.77 & (24.33) & $(0.56)$ & $(-0.100)$ \\
\hline \multirow[t]{4}{*}{$(3+)-(4+)$} & $\mathrm{V}(3+)$ & $(3 d)^{2}(J=2+)-(3 d)^{1}(J=3 / 2+)$ & 45.80 & 46.709 & 0.91 & \\
\hline & $\mathrm{Nb}(3+)$ & $(4 d)^{2}(J=2+)-(4 d)^{1}(J=3 / 2+)$ & 36.74 & 38.26 & 1.52 & 0.61 \\
\hline & $\operatorname{Ta}(3+)$ & $(5 d)^{2}(J=2+)-(5 d)^{1}(J=3 / 2+)$ & 35.03 & $(36.97)$ & $(1.94)$ & $(0.418)$ \\
\hline & $105(3+)$ & $(6 d)^{2}(J=2+)-(6 d)^{1}(J=3 / 2+)$ & 32.74 & $(34.90)$ & $(2.16)$ & $(0.226)$ \\
\hline \multirow[t]{4}{*}{$(4+)-(5+)$} & $V(4+)$ & $(3 d)^{1}(J=3 / 2+)-[$ Core $](J=0+)$ & 64.24 & 65.2822 & 1.04 & \\
\hline & $\mathrm{Nb}(4+)$ & $(4 d)^{1}(J=3 / 2+)-[$ Core $](J=0+)$ & 49.50 & 50.55 & 1.05 & 0.01 \\
\hline & $\mathrm{Ta}(4+)$ & $(5 d)^{1}(J=3 / 2+)-[$ Core $](J=0+)$ & 47.12 & 48.282 & 1.15 & 0.10 \\
\hline & $105(4+)$ & $(6 d)^{1}(J=3 / 2+)-[$ Core $](J=0+)$ & 43.57 & $(44.91)$ & $(1.34)$ & $(0.19)$ \\
\hline
\end{tabular}

figuration and a total angular momentum of $3 / 2$. The MCDF ground state for $\mathrm{Nb}(0)$ is 0.16 electron volts lower in energy than the MCDF state with a $(4 d)^{4}$ $(5 s)^{1}$ configuration and a total angular momentum of 1/2. The MCDF ground states of element 105 differ from other elements in the group. The element 105 ground states have more $s$ and $p_{1 / 2}$ electron character. This change results from relativistic effects $[16,17]$. This effect is clearly seen for the 105(1+), 105(2+), and $105(3+)$ ions.

Table 4 gives some excitation energies that were obtained by MCDF calculations. For each neutral atom or ion, a specific electronic excitation is given along with the corresponding MCDF energy of excitation. In most cases the corresponding experimentally obtained energy of excitation and difference between the MCDF and experimental excitation energies are given. The double energy differences given in Table 4 probably indicate the size of the uncertainty in the extrapolated ionization potentials that are presented in the next section, because these ionization potentials were obtained by using a similar double energy difference.

The solutions to the Dirac-Fock equation used did not yield ionization energies which were as accurate as desired. The accuracy of results was increased by using an extrapolation procedure. The extrapolation procedure used is based on ideas from finite difference methods in numerical analysis [18]. The independent variable is the principal quantum number and the function of interest of the principal quantum number is the quantity alpha. The value of the principal quantum number for vanadium, niobium, tantalum, and element 105 are $3,4,5$, and 6 , respectively and the quantity alpha for a specific atom or ion is equal to the experimental value of the ionization potential
Table 7. Single ionization potentials for element 105 in electron volts

Column I: MCDF calculations.

Column II: Extrapolated values.

\begin{tabular}{lrc}
\cline { 2 - 3 } Element & \multicolumn{1}{c}{ I } & \multicolumn{1}{c}{ II } \\
\hline 105 & 6.10 & $(7.4) \pm 0.4$ \\
$105(1+)$ & 14.82 & $(16.3) \pm 0.2$ \\
$105(2+)$ & 23.77 & $(24.3) \pm 0.2$ \\
$105(3+)$ & 32.74 & $(34.9) \pm 0.5$ \\
$105(4+)$ & 43.57 & $(44.9) \pm 0.1$ \\
\hline
\end{tabular}

minus the value of the MCDF ionization potential. Two assumptions were used to obtain the extrapolated ionization potentials of element 105 that are presented in Table 6. The first assumption is that alpha is a quadratic function of the principal quantum number. This assumption implies that $[\operatorname{beta}(m)$-beta $(m+1)]$ is the same for $m$ equal to 4 or 5 where $m$ is the value of the principal quantum number. The quantity beta $(m)$ is equal to [alpha $(m)$-alpha $(m-1)]$. The second assumption is that for $m$ equal to 3,4 , and 5 the ratio of beta $(m)$ for one charge state to beta $(m)$ of another charge stage is equal to the ratio of corresponding values of [beta $(m)$-beta $(m+1)]$. An assumption of this sort is necessary, because no accurate experimental values for the ionization potentials of $\mathrm{Ta}(1+)$, $\mathrm{Ta}(2+)$, and $\mathrm{Ta}(3+)$ are available. The first assumption is based on the periodic law of the chemical elements. The second assumption is justified when uncertainties of suitable size are associated with the ionization potentials obtained by extrapolation. The uncertainty is assumed to be equal to one-half of the absolute value of beta(4) plus one-half of the absolute value of [beta(4)-beta(5)]. 
Table 8. Multiple ionization potentials for group $5 b$ elements. The values in parentheses are estimates

\begin{tabular}{|c|c|c|c|c|c|c|}
\hline $\begin{array}{l}\text { Change } \\
\text { in } \\
\text { states }\end{array}$ & $\begin{array}{l}\text { Element } \\
\text { (q) }\end{array}$ & $\begin{array}{l}\text { Transition between } \\
\text { configurations } \\
\text { (see Table } 3 \text { ) }\end{array}$ & $\begin{array}{l}\text { MCDF } \\
\text { IP in } \\
\mathrm{eV}\end{array}$ & $\begin{array}{l}\text { Exp. } \\
\text { IP in } \\
\mathrm{eV}\end{array}$ & Alpha & Beta \\
\hline \multirow[t]{4}{*}{$(0)-(1+)$} & $\mathrm{V}(0)$ & $(3 d)^{3}(4 s)^{2}(J=3 / 2+)-(3 d)^{3}(4 s)^{1}(J=1+)$ & 6.58 & 6.74 & 0.16 & \\
\hline & $\mathrm{Nb}(0)$ & $(4 d)^{3}(5 s)^{2}(J=3 / 2+)-(4 d)^{4}(J=0+)$ & 6.18 & 6.8825 & 0.70 & 0.54 \\
\hline & $\mathrm{Ta}(0)$ & $(5 d)^{3}(6 s)^{2}(J=3 / 2+)-(5 d)^{3}(6 s)^{1}(J=1+)$ & 6.82 & 7.89 & 1.07 & 0.37 \\
\hline & $105(0)$ & $(6 d)^{3}(7 s)^{2}(J=3 / 2+)-(6 d)^{2}(7 s)^{2}(J=2+)$ & 6.10 & $(7.37)$ & $(1.27)$ & $(0.20)$ \\
\hline \multirow[t]{4}{*}{$(0)-(2+)$} & $\mathrm{V}(0)$ & $(3 d)^{3}(4 s)^{2}(J=3 / 2+)-(3 d)^{3}(J=3 / 2+)$ & 20.20 & 21.39 & 1.19 & \\
\hline & $\mathrm{Nb}(0)$ & $(4 d)^{3}(5 s)^{2}(J=3 / 2+)-(4 d)^{3}(J=3 / 2+)$ & 19.27 & 21.20 & 1.93 & 0.74 \\
\hline & $\mathrm{Ta}(0)$ & $(5 d)^{3}(6 s)^{2}(J=3 / 2+)-(5 d)^{3}(J=3 / 2+)$ & 20.93 & $(23.37)$ & $(2.44)$ & $(0.507)$ \\
\hline & $105(0)$ & $(6 d)^{3}(7 s)^{2}(J=3 / 2+)-(6 d)^{3}(J=3 / 2+)$ & 20.92 & $(23.63)$ & $(2.71)$ & $(0.274)$ \\
\hline \multirow[t]{4}{*}{$(0)-(3+)$} & $V(0)$ & $(3 d)^{3}(4 s)^{2}(J=3 / 2+)-(3 d)^{2}(J=2+)$ & 48.40 & 50.70 & 2.30 & \\
\hline & $\mathrm{Nb}(0)$ & $(4 d)^{3}(5 s)^{2}(J=3 / 2+)-(4 d)^{2}(J=2+)$ & 43.47 & 46.24 & 2.77 & 0.47 \\
\hline & $\mathrm{Ta}(0)$ & $(5 d)^{3}(6 s)^{2}(J=3 / 2+)-(5 d)^{2}(J=2+)$ & 43.99 & $(47.08)$ & $(3.09)$ & $(0.322)$ \\
\hline & $105(0)$ & $(6 d)^{3}(7 s)^{2}(J=3 / 2+)-(6 d)^{2}(J=2+)$ & 44.69 & $(47.96)$ & $(3.27)$ & $(0.174)$ \\
\hline \multirow[t]{4}{*}{$(0)-(4+)$} & $\mathrm{V}(0)$ & $(3 d)^{3}(4 s)^{2}(J=3 / 2+)-(3 d)^{1}(J=3 / 2+)$ & 94.20 & 97.41 & 3.21 & \\
\hline & $\mathrm{Nb}(0)$ & $(4 d)^{3}(5 s)^{2}(J=3 / 2+)-(4 d)^{1}(J=3 / 2+)$ & 80.21 & 84.50 & 4.29 & 1.08 \\
\hline & $\mathrm{Ta}(0)$ & $(5 d)^{3}(6 s)^{2}(J=3 / 2+)-(5 d)^{1}(J=3 / 2+)$ & 79.02 & $(84.05)$ & $(5.03)$ & $(0.740)$ \\
\hline & $105(0)$ & $(6 d)^{3}(7 s)^{2}(J=3 / 2+)-(6 d)^{1}(J=3 / 2+)$ & 77.43 & $(82.86)$ & $(5.43)$ & $(0.400)$ \\
\hline \multirow[t]{4}{*}{$(0)-(5+)$} & $\mathrm{V}(0)$ & $(3 d)^{3}(4 s)^{2}(J=3 / 2+)-[$ Core $](J=0+)$ & 158.43 & 162.69 & 4.26 & \\
\hline & $\mathrm{Nb}(0)$ & $(4 d)^{3}(5 s)^{2}(J=3 / 2+)-[$ Core $](J=0+)$ & 129.71 & 135.05 & 5.34 & 1.08 \\
\hline & $\mathrm{Ta}(0)$ & $(5 d)^{3}(6 s)^{2}(J=3 / 2+)-[$ Core $](J=0+)$ & 126.14 & $(132.22)$ & $(6.08)$ & $(0.740)$ \\
\hline & $105(0)$ & $(6 d)^{3}(7 s)^{2}(J=3 / 2+)-[$ Core $](J=0+)$ & 121.00 & $(127.48)$ & $(6.48)$ & $(0.400)$ \\
\hline
\end{tabular}

\section{Results}

In Table 5 some experimental values for ionization potentials of group $5 b$ elements are presented $[6,19]$. Accurate values of the ionization potential of tantalum are available only for the neutral atom and for $\mathrm{Ta}(4+)$. The table gives the ionization potentials in inverse centimeters and in electron volts. References for the values given are also presented.

Single ionization potentials for element 105 are presented in Table 6 . The table gives the change in charge state, the dominant initial and final electron configuration along with total angular momentum eigenvalue, the MCDF ionization potentials, the experimental or extrapolated ionization potentials, and alpha and beta values for the atoms and ions of interest. Table 6 illustrates the extrapolation procedure for the determination of ionization potentials. The MCDF ionization potentials were obtained from results in Table 3. The ionization potentials are energy differences between ground states. For example, the MCDF ionization potential of vanadium was obtained by subtracting the ground state energy of $\mathrm{V},-25791.379 \mathrm{eV}$, from the ground state energy of $\mathrm{V}(1+),-25784.801 \mathrm{eV}$. This gives $6.58 \mathrm{eV}$. Table 7 presents the MCDF and extrapolated ionization potentials for element 105. The uncertainties in the extrapolated ionization potentials are also included.

Multiple ionization potentials for element 105 are presented in Table 8. The table gives the change in charge state, the change in electronic state, the MCDF ionization potentials, the experimental or extrapolated ionization potentials, and alpha and beta values for the atoms and ions of interest. Table 8 illustrates the extrapolation procedure for the determination of multiple ionization potentials. The experimental multiple
Table 9. Multiple ionization potentials for element 105 in electron volts

Column I: MCDF calculations.

Column II: Extrapolation values.

\begin{tabular}{crr}
\hline $\begin{array}{c}\text { Change in } \\
\text { charge }\end{array}$ & \multicolumn{1}{c}{ I } & \multicolumn{1}{c}{ II } \\
\hline$(0)-(1+)$ & 6.10 & $(7.4) \pm 0.4$ \\
$(0)-(2+)$ & 20.92 & $(23.6) \pm 0.5$ \\
$(0)-(3+)$ & 44.69 & $(48.0) \pm 0.4$ \\
$(0)-(4+)$ & 77.43 & $(82.9) \pm 0.8$ \\
$(0)-(5+)$ & 121.00 & $(127.5) \pm 0.8$ \\
\hline
\end{tabular}

ionization potentials were obtained by the addition of the relevant single ionization potentials that are given in Table 5. Note that the value for $\mathrm{Ta}(1+)$ was not used in the extrapolations because of the relatively large uncertainty associated with this value. Table 9 presents the MCDF and extrapolated multiple ionization potentials with uncertainties for element 105.

Values for the ionic radii of element 105 presented here were obtained by using the location of the maximum of the charge density [20, 21], RMAX, in the $m p$ orbitals of vanadium, niobium, tantalum, and element 105 and an extrapolation procedure [4]. The extrapolation procedure is very similar to that used to obtain extrapolated values of the ionization potentials. Some of the assumptions in the two procedures differ. The quantity RMAX is the location of the maximum in $r^{2} R(r)^{2}$ where $R(r)$ is the radial part of the wavefunction for the $m p$ orbital and $r$ is the distance from the origin. The values of RMAX for $\mathrm{V}, \mathrm{Nb}, \mathrm{Ta}$, and element 105 for neutral atoms and for ions of charge +1 to +5 are given in Table 10 . 
Table 10. Determination of the ionic radii in nanometers of the neutral atoms and of the $+1,+2,+3,+4$, and +5 charged ions of element 105 by extrapolation of the radii of maximum charge density of mp orbitals. The value of $m$ is equal to $3,4,5$, and 6 for vanadium, niobium, tantalum, and element 105 , respectively. The values in parentheses are estimates

\begin{tabular}{|c|c|c|c|c|c|}
\hline Element & Charge & RMAX & $\begin{array}{l}\text { Atomic or } \\
\text { ionic radius }\end{array}$ & Alpha & Beta \\
\hline V & 0 & 0.0451 & - & & \\
\hline $\mathrm{Nb}$ & 0 & 0.0598 & - & & \\
\hline $\mathrm{Ta}$ & 0 & 0.0613 & - & & \\
\hline 105 & 0 & 0.0694 & - & & \\
\hline $\mathrm{V}$ & +1 & 0.0451 & - & & \\
\hline $\mathrm{Nb}$ & +1 & 0.0601 & - & & \\
\hline Ta & +1 & 0.0613 & - & & \\
\hline 105 & +1 & 0.0693 & - & & \\
\hline $\mathrm{V}$ & +2 & 0.0451 & 0.079 & 0.0339 & \\
\hline $\mathrm{Nb}$ & +2 & 0.0599 & $(0.0870)$ & $(0.0271)$ & $(0.0068)$ \\
\hline $\mathrm{Ta}$ & +2 & 0.0613 & $(0.0868)$ & $(0.0255)$ & $(0.0016)$ \\
\hline 105 & +2 & 0.0692 & $(0.0983)$ & $(0.0291)$ & $(-0.0036)$ \\
\hline $\mathrm{V}$ & +3 & 0.0447 & 0.0640 & 0.0193 & \\
\hline $\mathrm{Nb}$ & +3 & 0.0595 & 0.072 & 0.0125 & 0.0068 \\
\hline $\mathrm{Ta}$ & +3 & 0.0611 & 0.072 & 0.0109 & 0.0016 \\
\hline 105 & +3 & 0.0691 & $(0.0836)$ & $(0.0145)$ & $(-0.0036)$ \\
\hline $\mathrm{V}$ & +4 & 0.0452 & 0.058 & 0.0128 & \\
\hline $\mathrm{Nb}$ & +4 & 0.0591 & 0.068 & 0.0089 & 0.0039 \\
\hline $\mathrm{Ta}$ & +4 & 0.0608 & 0.068 & 0.0072 & 0.0017 \\
\hline 105 & +4 & 0.0688 & $(0.0765)$ & $(0.0077)$ & $(-0.0005)$ \\
\hline $\mathrm{V}$ & +5 & 0.0435 & 0.054 & 0.0105 & \\
\hline $\mathrm{Nb}$ & +5 & 0.0586 & 0.064 & 0.0054 & 0.0051 \\
\hline $\mathrm{Ta}$ & +5 & 0.0604 & 0.064 & 0.0036 & 0.0018 \\
\hline 105 & +5 & 0.0685 & $(0.0736)$ & $(0.0051)$ & $(-0.0015)$ \\
\hline
\end{tabular}

The extrapolation procedure used to obtain radii of ions of element 105 is illustrated in Table 10. In Table 10 an alpha value is equal to the difference between the corresponding values of the ionic radius and RMAX. The value of beta is equal to [alpha $(m-1)-$ alpha $(m)$ ]. Beta values for element 105 were obtained by extrapolation of these values for niobium and tantalum. Experimental values for the radii of neutral atoms and of ions with a charge of +1 are not available for any of the group $5 b$ elements [22]. Also, ionic radii for the ion of niobium and tantalum with a charge of +2 are not available [22]. Experimental values for the radii of ions presented in Table 10 were obtained from reference 22.

Two assumptions were used to obtain the radii of element 105 ions presented in Table 10. The first assumption is that alpha is a quadratic function of the principal quantum number. This assumption was also used to obtained extrapolated values for the ionization potentials. The second assumption is that beta $(m)$ for the +2 charged state is the same as beta $(m)$ for the +3 charged state. The assumptions are justified when uncertainties of suitable size are associated with the radii obtained by extrapolation. The values of the uncertainties for the radii were obtained in the same manner in which they were obtained for ionization potentials. The values in parentheses in Table 10 are estimates. In Table 11 values of RMAX and radii along with uncertainties are presented for the $+2,+3$, +4 , and +5 charged ions of element 105 .
Table 11. Ionic radii in nanometers for the $+2,+3,+4$, and +5 ions of element 105

Column I: Extrapolated values for the ionic radii.

\begin{tabular}{ccc}
\hline Ion & RMAX & I \\
\hline $105(2+)$ & 0.0692 & $0.098 \pm 0.006$ \\
$105(3+)$ & 0.0691 & $0.084 \pm 0.006$ \\
$105(4+)$ & 0.0688 & $0.077 \pm 0.004$ \\
$105(5+)$ & 0.0685 & $0.074 \pm 0.005$ \\
\hline
\end{tabular}

The ionization potentials given in Table 9 and the ionic radii given in Table 11 were used to determine some standard electrode potentials for element 105 . These determinations were based on Born-Haber cycles [23]. The standard electrode potential, $E^{0}$, for the following reaction

$$
\mathrm{M}^{n+}+[(n-m) / 2] \mathrm{H}_{2}=\mathrm{M}^{m+}+(n-m) \mathrm{H}^{+}
$$

for $n$ greater than $m$ is

$$
E^{0}=-\Delta G^{0} /[(n-m) F]
$$

where $\Delta G^{0}$ is the standard Gibbs free energy change for the reaction and $F=96.5220 \mathrm{~kJ} / \mathrm{mole}$-volt. The above reaction is denoted in Table 12 by $\mathrm{M}^{n+} / \mathrm{M}^{m+}$. Here $\mathrm{M}$ denotes element 105.

The Born-Haber cycles used require the enthalpy of sublimation, the first five ionization potentials, and the Gibbs free energy of hydration of several ions of element 105 . The value of the enthalpy of sublimation 
Table 12. Standard electrode potentials in volts at $298.15 \mathrm{~K}$ for element 105 from the Born-Bjerrum equation and the BratschLagowski equations

Column I: Born-Bjerrum equation.

Column II: Bratsch-Lagowski equations.

\begin{tabular}{crc}
\hline Electrode & \multicolumn{1}{c}{ I } & II \\
\hline$(105)^{2+} /(105)$ & 3.04 & 3.03 \\
$(105)^{3+} /(105)$ & 0.87 & 1.38 \\
$(105)^{4+} /(105)$ & -0.14 & 0.80 \\
$(105)^{5+} /(105)$ & -0.73 & - \\
$(105)^{3+} /(105)^{2+}$ & -3.47 & -1.92 \\
$(105)^{4+} /(105)^{3+}$ & -3.17 & -0.94 \\
$(105)^{5+} /(105)^{4+}$ & -3.09 & - \\
\hline
\end{tabular}

used for element 105 was $795 \mathrm{~kJ} /$ mole. This value was given in reference 24 . The sum of the first two, first three, first four, and first five ionization potentials for element 105 are given in Table 9. The Gibbs free energies of hydration were obtained using a form of the Born equation [23]. This equation is

$$
\Delta G_{\mathrm{sin}}^{0}=-B Z^{2} /(r+w)+7.9 \mathrm{~kJ} / \text { mole }
$$

where $\Delta G_{\mathrm{sln}}$ is the Gibbs free energy of hydration of the ion of interest, $B$ and $w$ are parameters, $Z$ is the charge of the ion of interest in electron units, and $r$ is the ionic radius of the ion. Here $B$ is equal to 68583 $\mathrm{kJ} /$ mole-picometer, $w$ is equal to 80 picometers for cations and it is equal to 17 picometers for anions. The values used for $r$ are presented in Table 11. The standard Gibbs free energy of formation of the hydrogen ion in water and of the gaseous hydrogen ion are $-1066.0 \mathrm{~kJ} / \mathrm{mole}$ and $132.2 \mathrm{~kJ} / \mathrm{mole}$, respectively. These values are given in references 25 and 26 .

The standard electrode potentials obtained for element 105 are presented in Table 12. The electrode potentials indicate that the +2 and +3 charged ions are unstable and the +4 and +5 charged ions are stable in acid solution at standard conditions with respect to the metal. In acid solutions the +5 charged ion of element 105 is more stable than the other ions studied.

\section{Conclusions}

The uncertainties in the ionization potentials for element 105 presented here are larger than those associated with the ionization potentials calculated [1] for element 104, because accurate experimental values for the ionization potentials of $\mathrm{Ta}(1+), \mathrm{Ta}(2+)$, and $\mathrm{Ta}(3+)$ are not available.

The ionization potentials and ionic radii presented here may be used to predict certain chemical properties of compounds of element 105 and of element 105 ions in solution. For compounds and ions with an oxidation state of $+2,+3$, and +4 the methods presented in reference 11 may be used for these predictions. For other oxidation states the basic Born-Haber cycle approach may be used $[9,10,23]$. Some standard electrode potentials are presented for element 105.
Except for $\mathrm{Nb}$ and $\mathrm{V}(1+)$, the relativistic multiconfiguration Dirac-Fock (MCDF) total angular momentum eigenvalues and dominant configuration calculated for the lowest energy state agree with the experimental results. For element 104 this agreement was obtained in all cases [1]. This indicates that the MCDF results are rather reliable for these two properties. MCDF results and extrapolation procedures were used to obtain the ionization potentials and ionic radii presented here. The procedure also yielded values for the ionization potentials of $\mathrm{Ta}(1+)$, $\mathrm{Ta}(2+)$, and $\mathrm{Ta}(3+)$. Accurate values for these quantities have not been obtained experimentally $[6,7,8]$. The extrapolation procedure yielded values for the radii of $\mathrm{Nb}(2+)$ and $\mathrm{Ta}(2+)$ also. Accurate experimental values for these radii are not available [22].

\section{Acknowledgements}

The authors appreciate the advice and guidance provided by Dr. O. L. Keller, Jr. on the work presented. The research was sponsored by the Division of Chemical Sciences, Office of Basic Energy Sciences, U.S. Department of Energy under contract DE-AC0584OR21400 with Martin Marietta Energy Systems, Inc., the Deutsche Forschungsgemeinschaft (DFG), the Wilhelm and Else Heraeus Stiftung, and the Gesellschaft für Schwerionenforschung (GSI), Darmstadt. The work was supported by the Florida State University Supercomputer Computations Research Institute which is partially funded by the U.S. Department of Energy through contract DE-FC05$85 \mathrm{ER} 25000$.

\section{References}

1. Johnson, E., Fricke, B., Keller, O. L., Nestor, C. W., Tucker, T. C.: Ionization Potentials and Radii of Atoms and Ions of Element 104 (unnilquadium) and of Hafnium(2+) Derived from Multiconfiguration Dirac-Fock Calculations. J. Chem. Phys. 93, 8041 (1990).

2. Grant, I. P.: Relativistic Calculation of Atomic Structures. Adv. Phys. 19, 747 (1970).

3. Grant, I. P., Quiney, H. M.: Foundations of the Relativistic Theory of Atomic and Molecular Structure. Adv. Atom Mol. Phys. 23, 37 (1988).

4. Johnson, E., Fricke, B.: Prediction of Some Thermodynamic Properties of Selected Compounds of Element 104. J. Phys. Chem. 95, 7082 (1991).

5. Desclaux, J.-P.: A Multiconfiguration Relativistic DiracFock Program. Comput. Phys. Commun. 9, 31 (1975).

6. Moore, Charlotte E.: Atomic Energy Levels, NSRDS-NBS, SD Catalog No. C 13.48:35, Nat. Stand. Ref. Data. Ser., Nat. Bur. Stand., Washington, D. C. 1971.

7. Man, K. F., Smith, A. C. H., Harrison, M. F. A.: A Measurement of the Cross Section for Ionization of $\mathrm{Ta}^{+}$by Electron Impact. J. Phys. B 20, 4895 (1987).

8. Sugar, J., Kaufman, V.: Nuclear Magnetic Dipole Moment of ${ }^{181}$ Ta. Phys. Rev. C 12, 1336 (1975).

9. Cunningham, B. B.: Chemistry of Actinide and Transactinide Elements. In: Proceedings of the Robert A. Welch Foundation Conference on Chemical Research XIII, The Transuranium Elements (W. O. Milligan, ed.). Robert A. Welch Foundation, Houston 1970. 
10. Keller, O. L., Nestor, C. W., Fricke, B.: Predicted Properties of the Superheavy Elements. III. Element 115, Eka-Bismuth. J. Phys. Chem. 78, 1945 (1974).

11. Bratsch, S. G., Lagowski, J. J.: Actinide Thermodynamic Predictions. 3. Thermodynamics of Compounds and Aquo Ions of the $2+, 3+$, and $4+$ Oxidation States and Standard Electrode Potentials at 298.15 K. J. Phys. Chem. 90, 307 (1986).

12. Zvara, I., Eichler, B., Belov, V. Z., Zvarova, T. S., Korotkin, Yu. S., Shalaevskii, M. R., Schchegolev, V. A., Hussonois, M.: Gas Chromatography and Thermochromatography in the Study of Transuranium Elements. Sov. Radiochem. 16, 709 (1974).

13. Zvara, I., Belov, V. Z., Domanov, V. P., Shalaevskii, M. R.: Chemical Isolation of Nilsbohrium as Ekatantalum in the Form of the Anhydrous Bromide II. Experiments with a Spontaneously Fissioning Isotope of Nilsbohrium. Sov. Radiochem. 18, 328 (1976).

14. Gregorich, K. E., Henderson, R. A., Lee, D. M., Nurmia, M. J., Chasteler, R. M., Hall, H. L., Bennett, D. A., Gannett, C. M., Chadwick, R. R., Leyba, J. D., Hoffman, D. C., Herrmann, G.: Aqueous Chemistry of Element 105. Radiochim. Acta 43, 223 (1988).

15. Fischer, C. F.: The Hartree-Fock Method for Atoms, Wiley, New York 1977.

16. Pitzer, K. S.: Relativistic Effects on Chemical Properties. Acc. Chem. Res. 12, 271 (1979).

17. Pyykko, P., Desclaux, J.-P.: Relativity and the Periodic System of Elements. Acc. Chem. Res. 12, 276 (1979).
18. Booth, Andrew, D.: Numerical Methods, 3rd ed., Butterworths, London 1966, pp. 7-11.

19. a) Handbook of Chemistry and Physics, 68th ed., 1987-88, Chemical Rubber Co. Press, Inc., Boca Raton, Florida 1987, pp. E-77, E-78. b) J. Sugar and C. Corliss: Energy Levels of Vanadium, V i through V xiii, J. Chem. Phys. Ref. Data 7, 1191 (1978).

20. Slater, J. C.: Quantum Theory of Molecules and Solids, Volume 2, McGraw-Hill Book Co., New York 1965, Chapter 4.

21. Slater, J. C.: Atomic Radii in Crystals. J. Chem. Phys. 41, 3199 (1964).

22. Shannon, R. D.: Revised Effective Ionic Radii and Systematic Studies of Interatomic Distances in Halides and Chalcogenides. Acta Crystallogr. A 32, 751 (1976).

23. Johnson, D. A.: Some Thermodynamic Aspects of Inorganic Chemistry, 2nd ed., Cambridge University Press, New York 1982.

24. Seaborg, G. T., Keller, O. L.: Future Elements (including superheavy elements). In: The Chemistry of the Actinide Elements, Volume 2, 2nd ed. (J. J. Katz, G. T. Seaborg, and L. R. Morss, editors). Chapman and Hill, New York 1986, p. 1637.

25. Conway, B. E.: The Evaluation and Use of Properties of Individual Ions in Solution. J. Solution Chem. 7, 721 (1978).

26. Bratsch, S. G., Lagowski, J. J.: On the Existence of $\mathrm{Na}^{-}$in Liquid Ammonia. J. Phys. Chem. 88, 1086 (1984). 